\title{
ANALISA KEGAGALAN POLISHED ROD PADA POMPA ANGGUK
}

\section{FAILURE ANAL YSIS OF POLISHED ROD IN SUCKER ROD PUMP}

\author{
Eka Febriyanti, Amin Suhadi, Laili Novita Sari \\ Balai Besar Teknologi Kekuatan Struktur (B2TKS) - BPPT \\ Kawasan Puspitek Serpong Tangerang 15314 \\ e-mail : eka.febriyanti@bppt.go.id, amin.suhadi@bppt.goid, laili.novita@bppt.go.id
}

\begin{abstract}
Abstrak
Tulisan ini membahas tentang kerusakan polished rod akibat material yang digunakannya bersifat getas dan memiliki mikrostruktur yang tidak homogen. Pemeriksaan pada polished rod dari pompa angguk menggunakan metode pengamatan visual, fraktografi makro, metalografi, uji kekerasan, analisa komposisi kimia, pemeriksaan SEM, serta uji komposisi produk korosi dengan EDS. Hasil pemeriksaan visual dan uji penetran menunjukkan adanya retak melintang yang menyebar pada satu sisi permukaan polished rod menunjukkan bahwa polished rod mengalami pembebanan bending sebelum patah. Sedangkan hasil pemeriksaan fraktografi memperlihatkan adanya daerah patahan getas dengan pola radial mark yang menandakan bahwa jenis pembebanan merupakan beban statis dengan alur perambatan yang berlangsung cepat. Selain itu, hasil pengamatan metalografi memperlihatkan bahwa struktur mikro pada polished rod bersifat tidak homogen yang terdiri atas ferit-perlit, bainit, dan martensit yang bersifat getas. Jadi, dapat disimpulkan bahwa penyebab kerusakan adalah ketidakhomogenan pada mikrostruktur dan sifat material yang bersifat getas yang berperan sebagai konsentrasi tegangan ditambah dengan tertahannya sistem kerja pompa angguk yang menyebabkan satu sisi polished rod mengalami pembebanan bending sampai material tidak mampu lagi menahan beban lalu patah.
\end{abstract}

Kata Kunci : Pompa angguk, Polished rod, Getas, Bending, Patah

\begin{abstract}
This paper discusses about failure of a polished rod because its material is brittle and has inhomogenous microstructure.Tests and examinations of polished rod on sucker rod were carried out to such as visual and macro fractography examination, metallography examination, hardness testing, chemical composition analysis of polished rod material, SEM and EDS examination. Visual examination and penetrant test results show the presence of transverse crack that spread on one side of the polished rod surfaces indicates that the polished rod was subjected to bending load before it is fractured. While the results of fractographic examination showed the presence of brittle fracture with radial mark pattern that indicates that the type of loading was a static loading with fast crack propagation. In addition, metallographic observation shows that the microstructure of polished rods is inhomogeneous namely ferrite-pearlite, bainite, and brittle martensite. Thus, it can be concluded that the cause of the damage was the non-homogenity of the microstructure and the brittle of the polished rod material which acts as the stress concentration. With the retention of sucker rod pump system causes one side of the polished rod to impose bending load until the material is no longer able to withstand the load and then fracture.
\end{abstract}

Keywords : Sucker rod pump, Polished rod, Brittle, Bending, Fracture

Diterima (received) : 09 November 2019, Direvisi (revised ) : 05 April 2019 ,

Disetujui (accepted) : 18 April 2019 


\section{PENDAHULUAN}

Pada industri minyak dan gas bumi, pompa angguk (sucker rod) merupakan salah satu alat yang dipakai untuk menaikkan minyak bumi dari dalam sumur ke permukaan tanah. Metode pompa dipakai untuk sumursumur yang sudah tidak memiliki tekanan yang cukup untuk menaikkan atau mengalirkan minyak bumi sampai ke permukaan ${ }^{1}$.

Prinsip kerja pompa angguk (sucker rod) adalah mengubah gerak putar pada prime mover menjadi gerak naik turun, sehingga menyebabkan pompa bisa bekerja menaikkan minyak bumi dari dalam sumur ke atas permukaan ${ }^{1)}$.

Pompa angguk (sucker rod) memiliki salah satu bagian terpenting yaitu polished rod. Polished rod merupakan stang penghubung antara pumping unit di permukaan tanah (carrier bar) dengan rangkaian pompa yang berada di dalam sumur (sucker rod string) dan bergerak naikturun di dalam stuffing box seperti yang terlihat dalam ilustrasi pompa angguk (sucker rod) (Gambar 1) 2).

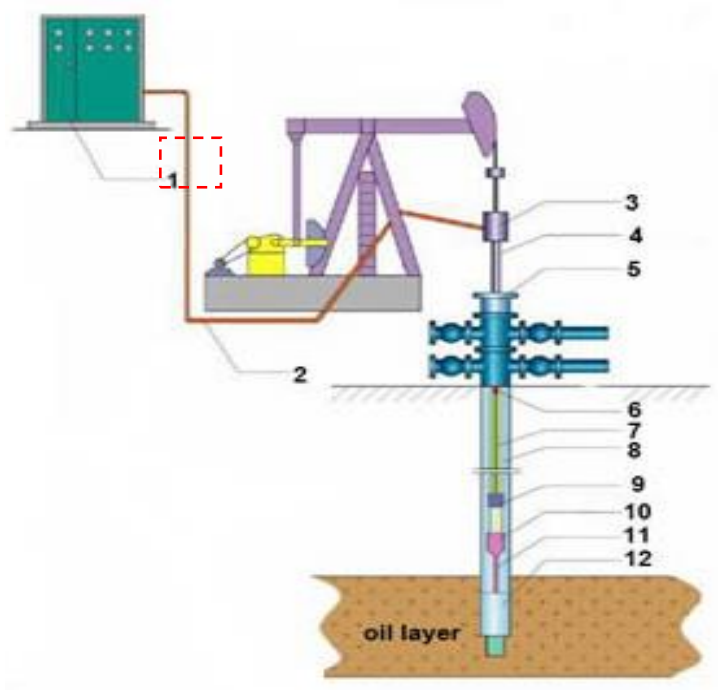

Keterangan :

1. Control cabinet; 2.Secondary cable;

3. Hanger connector; 4. Hollow polished rod;

5.Stuffing box; 6.Sensor; 7. Whole cable;

8. Hollow sucker rod; 9. Terminator; 10.

Adaptor connector; 11 . Solid sucker rod;

12. Oil well pump

Gambar 1.

Bagian-bagian Pompa Angguk (sucker rod) ${ }^{1)}$
Polished rod merupakan bagian dari rod string dalam sistem pompa angguk (sucker rod) yang berfungsi untuk menahan beban maksimum dari seluruh rangkaian dan fluida, menahan gaya lain akibat gerakan horse head, dan serangan cairan dari sumur yang mudah membentuk karat ${ }^{2}$.

Standar diameter polished rod menurut API 11B adalah 1", 1 1/8", 1 1/4", dan 1 1/2" dengan standar panjang polished rod adalah 8', 11', 16', dan 22'. Polished rod diklem pada carrier bar yang dihubungkan dengan horse head melalui wireline hanger yang bersifat fleksible agar polished rod tetap tegak lurus dalam stuffing box. Oleh karena itu, polished rod harus diselaraskan dengan benar pada pumping tee. Keselarasan (allignment) polished rod yang buruk akan mengakibatkan berkurangnya umur stuffing box dan kemungkinan kegagalan pada polished rod ${ }^{1-2)}$

Setelah 2 bulan instalasi, polished rod pada pompa sucker rod (angguk) di salah satu area sumur minyak milik sebuah perusahaan mengalami patah pada posisi di bawah hanger atau pegangannya sedikit. Lalu polished rod yang patah dibawa ke laboratorium analisa kerusakan dan umur sisa untuk diketahui penyebab terjadinya patah pada polished rod tersebut.

Tujuan penelitian masalah perpatahan pada polished rod yaitu :

- Mengidentifikasi penyebab kerusakan dan perpatahan polished rod sehingga dapat dilakukan langkah-langkah penanggulangan selanjutnya untuk mencegah terjadinya pengulangan kerusakan yang sejenis.

- Membandingkan karakteristik material polished rod yang diperiksa di laboratorium uji dengan spesifikasi standard material yang diinginkan.

\section{BAHAN DAN METODE}

\section{Bahan}

Material yang digunakan dalam penelitian ini adalah adalah polished rod yang mengalami patah pada posisi sedikit di bawah hanger (kotak bergaris putus-putus di Gambar 2). 


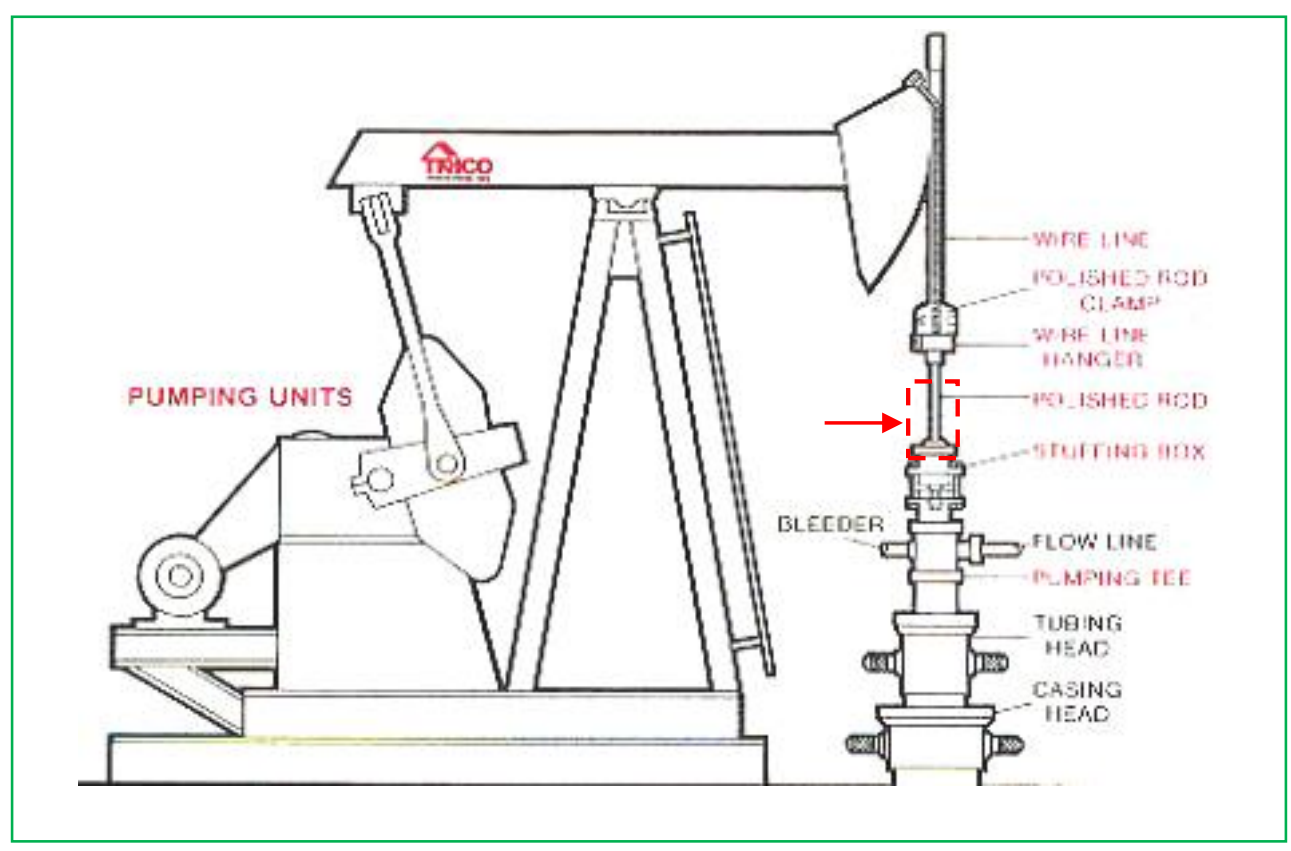

Gambar 2.

Diagram Pompa Angguk (sucker rod) Penyelesaian Sumur Area XXX dan Posisi Polished Rod Ø $31,75 \mathrm{~mm}$ pada kondisi terpasang.

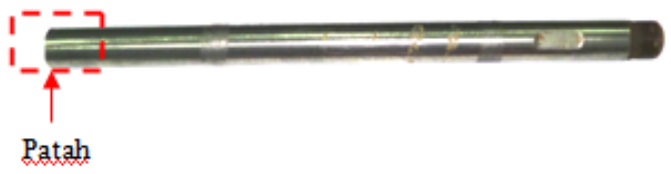

Gambar 3.

Polished Rod mengalami patah pada posisi sedikit di bawah hanger

\section{Spesifikasi Bahan}

Tabel 1. Spesifikasi Polished Rod

\begin{tabular}{ll}
\hline Material (body) & $\begin{array}{l}\text { Alloy steel dengan } \\
\text { surface treatment } \\
\text { (spray metal } \\
\text { coated) }\end{array}$ \\
\hline Bentuk & Round bar \\
Diameter & $31,75 \mathrm{~mm}$ \\
Panjang & $6,7 \mathrm{~m}$ \\
Umur pakai & 2 bulan \\
Waktu patah & Awal oktober 2017 \\
\hline
\end{tabular}

\section{Metode Pengujian}

Setelah dilakukan proses pemotongan pada polished rod yang mengalami patah pada posisi sedikit di bawah hanger dilanjutkan ke tahapan selanjutnya yaitu pengujian. Pengujian yang dilakukan meliputi pemeriksaan visual pada daerah yang patah, pemeriksaan makro fraktografi, pemeriksaan mikrostruktur, pengujian kekerasan, analisis komposisi kimia base metal material polished rod, pemeriksaan dengan Scanning Electron Microscopy (SEM), serta uji komposisi produk korosi dengan metode Energy Dispersive $X$ ray (EDX) Analysis di permukaan patahan polished rod.

Pemeriksaan visual dilakukan untuk mengidentifikasi lokasi patah, bentuk kerusakan, dan untuk menentukan daerah awal penyebab patah yang nantinya dipilih untuk pemeriksaan lebih mendalam. Metode ini dilakukan dengan memeriksa kondisi dan kontur daerah yang rusak secara akurat lalu didokumentasikan dengan kamera digital.

Bersamaan dengan pemeriksaan visual, pemeriksaan makro fraktografi menggunakan mikroskop stereo untuk mengidentifikasi awal patah di permukaan daerah patah sehingga area tersebut dapat diekspos pada perbesaran yang lebih tinggi dibandingkan pemeriksaan visual, sehinggal informasi lebih dapat diperoleh dari hasil pemeriksaan makrografi. Pemeriksaan makrografi dilakukan dengan perbesaran 12x-50x.

Pemeriksaan metalografi menggunakan mikroskop optic dilakukan untuk memeriksa 
awal patah lebih detail dan sekeliling daerah patah yang berhubungan dengan mikrostruktur dan perubahannya selama proses pengoperasian. Sebagai tambahan, pemeriksaan metalografi dilakukan untuk memeriksa kemungkinan adanya void mikro, retak mikro, ataupun cacat mikro lainnya yang mungkin ada dan berpengaruh sebagai penyebab perpatahan pada polished rod. Hasilnya lalu didokumentasikan dengan kamera digital. Persiapan benda uji metalografi mengacu pada standard ASTM E 3-013) yang meliputi beberapa tahapan antara lain :

1. Pemotongan benda uji metalografi berupa material polished rod menggunakan gerinda tangan Makita

2. Proses pembentukan/ pencetakan sampel uji menggunakan bubuk technovit atau acryfix yang dicampur dengan cairan pengeras dengan perbandingan tertentu, dimana campuran cairan tersebut menjadi keras perlu waktu \pm 1 jam.

3. Proses grinding/pengampelasan menggunakan mesin grinding tangan Struers dan kertas ampelas silicon karbida (SiC) dengan berbagai kekasaran, yaitu kombinasi dari 80,120, 220, 360, 500, 600, 800,1000 , dan 1200

4. Proses pencucian menggunakan alkohol $95 \%$ kemudian dikeringkan dengan peralatan pengering (hair dryer).

5. Proses polishing/pemolesan sampel uji pipa memanfaatkan diamond bentuk pasta.

Selanjutnya dilakukan proses mikroetsa sampel uji pipa yang mengacu pada standard ASTM E 407-074). Tahapannya adalah sebagai berikut :

1. Menyiapkan zat etsa nital $2 \%$

2. Menggosokan sampel uji pipa dengan kapas dan gunting kawat, berkali sampai terjadi perubahan warna

3. Mencuci benda uji pipa dengan alkohol.

4. Mendokumentasikan sampel uji dengan menggunakan kamera mikro digital dengan perbesaran $100 x, 200 x$, dan 500 $x$, yang dilengkapi dengan mistar pengukur sebagai pembanding.

Pengujian kekerasan dari polished rod dilakukan di sekeliling daerah patah untuk mengetahui kemungkinan terjadinya perubahan nilai kekerasan yang mungkin menyebabkan patah ataupun untuk menemukan adanya bukti work hardening akibat deformasi. Metode yang digunakan yaitu metode indentasi vickers microhardness mengacu pada SNI 19-0409-19895). Beban

yang digunakan adalah $5 \mathrm{kgf}$ dengan menggunakan indentor intan. Metode Vickers menggunakan alat yang disebut vickers microhardness tester kemudian hasil yang didapat diukur dengan mikroskop dan dihitung dengan menggunakan tabel nilai kekerasan Hardness Vickers (HV).

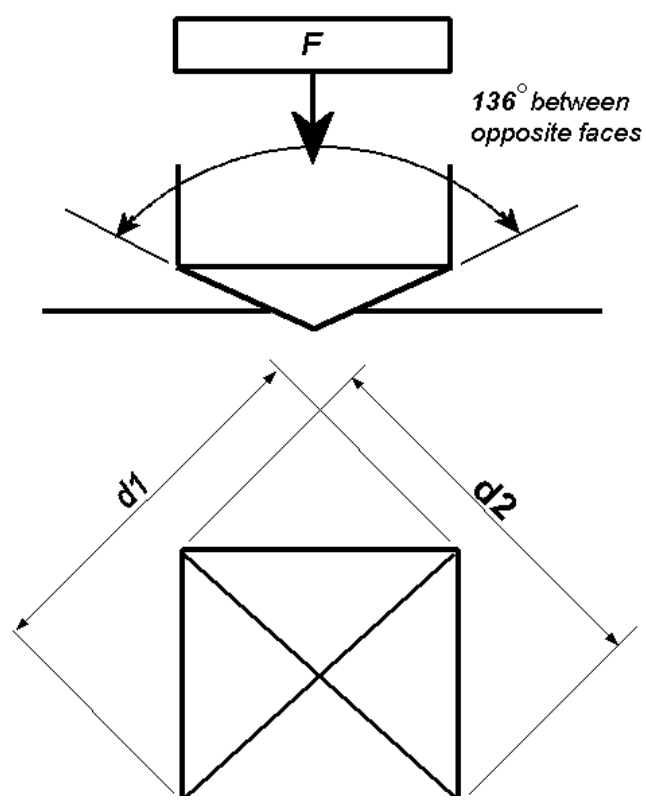

Gambar 4

Ilustrasi Pengujian Kekerasan dengan Metode Vickers ${ }^{6)}$

Analisis komposisi kimia terhadap polished rod menggunakan alat Optical Emission Spectrometric (OES). Pemeriksaan dilakukan untuk membandingkan komposisi kimia material dasar terhadap material standard base metal untuk polished rod (API 11B). Selain itu, pengujian juga digunakan untuk mengevaluasi terjadinya kemungkinan degradasi material. Pemeriksaan komposisi kimia mengacu pada standard ASTM E 415$17^{7)}$.

Pengujian komposisi kimia sampel uji polished rod yang mengalami perpatahan dengan metode OES terdiri atas beberapa tahapan yaitu :

1. Mempersiapkan alat uji OES

2. Melakukan pengkalibrasian data

3. Melakukan preparasi terhadap sampel uji pipa dengan cara melakukan grinding dan mengamplas dengan kekasaran $40 \mathrm{CCW}$.

4. Menempelkan ujung probe pada permukaan sample uji yang sudah dipreparasi dan tekan tombol trigger sampai proses pembakaran selesai \pm 10 detik.

5. Melihat hasil pembakaran pada layar monitor.

6. Melakukan pembakaran sekurangkurangnya 3 kali 
7. Mengkalkulasi dan melaporkan data ratarata hasil pengujian lalu dibuat print out

8. Mematikan alat dengan menutup kran regulator gas Argon sehingga jarum menunjukkan angka nol pada regulator.

9. Memutar tombol utama pada posisi off

Pengujian tarik dilakukan pada daerah sekeliling patahan polished rod bertujuan untuk mengetahui adanya perubahan terhadap standar nilai kekuatan tarik untuk polished rod (API 11B).

Sampel uji tarik mengacu pada standard ASTM E8 ${ }^{8)}$ dengan menggunakan mesin uji tarik Servopulser Shimadzu. Sedangkan sampel dari material yang digunakan untuk pengujian tarik seperti ditunjukkan pada Gambar 5.

Untuk menghitung nilai kekuatan tarik maksimum (UTS, ultimate tensile strength),

kekuatan luluh (YS, yield strength), dan $\varepsilon$ (elongasi) dari material material polished rod menggunakan persamaan sebagai berikut6):

$$
\begin{aligned}
& g_{u T S}=\text { Fmax } / A_{0} \\
& \varepsilon=\left(\operatorname{lmax}-I_{0}\right) / l o
\end{aligned}
$$

Analisis SEM dilakukan pada permukaan patahan polished rod untuk memeriksa bentuk dan jenis patahan serta untuk menemukan bukti lain yang mungkin ada dan berperan pada awal kerusakan.

Analisa unsur pada daerah patahan menggunakan metode Energy Dispersive Analysis $X$-ray (EDX) untuk memeriksa adanya elemen/unsur mencurigakan seperti ion agresif/ion korosif yang mungkin berperan pada perpatahan polished rod.

Metode pengujian dan pemeriksaan terhadap polished rod secara jelas dapat dilihat dengan flowsheet (lembar alir) pada Gambar 6.

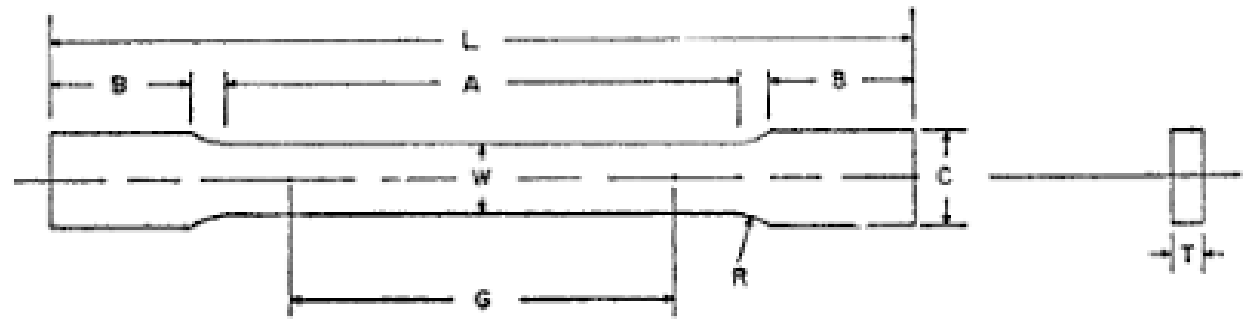

Gambar 5.

Sampel Uji Tarik dari Polished Rod dimana $L=$ Minimal $100 \mathrm{~mm}, \mathrm{G}=25 \mathrm{~mm}$, dan $\mathrm{C}=10 \mathrm{~mm}$

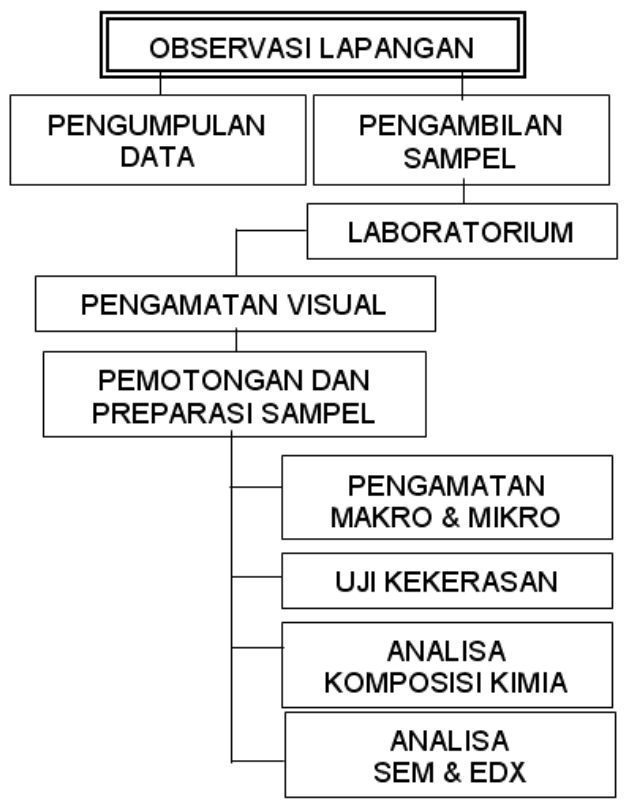

Gambar 6.

Flowsheet (Lembar Alir) Pemeriksaan dan Pengujian terhadap Polished Rod

\section{HASIL DAN PEMBAHASAN}

\section{Hasil Pemeriksaan Fraktografi Makro}

Dari pemeriksaan fraktografi makro maka ditemukan bahwa bentuk permukaan patahan polished rod kode putih berupa patah getas dengan pola radial mark yang dapat dilihat alur-alur halus yang menginformasikan terjadinya rambatan perpatahan ${ }^{1-2)}$ dan patah sisa (Gambar 7). Selain itu, daerah patah getas pada polished rod memiliki daerah yang lebih luas dibandingkan daerah patah sisa (Gambar 7). Jadi, permukaan polished rod mengalami patah getas akibat bending load (Gambar 8-9). Daerah coating layer baik pada awal patah maupun patah akhir terlihat masih jelas permukaan patahannya (Gambar 10-11) dengan ketebalan coating layer sebesar 0,425 mm (Gambar 12).

Sedangkan untuk hasil uji penetran pada permukaan luar polished rod menunjukkan adanya retak melintang dengan arah sumbu rod hanya pada satu sisi (Gambar 13). Retak melintang yang menyebar di permukaan 
polished rod merupakan indikasi munculnya retak sekunder. Retak melintang yang muncul pada satu sisi menunjukkan bahwa polished rod kode putih mengalami pembebanan bending sebelum patah.

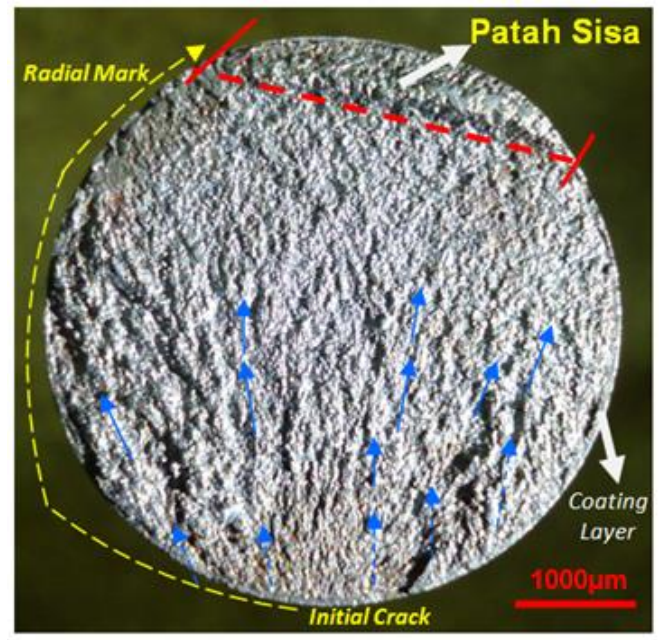

Gambar 7.

Bentuk permukaan patahan Polished Rod berupa patah getas dan terdapat patah sisa. Pola patah getas dengan Radial Mark dapat dilihat alur-alur halus yang menginformasikan terjadinya rambatan perpatahan
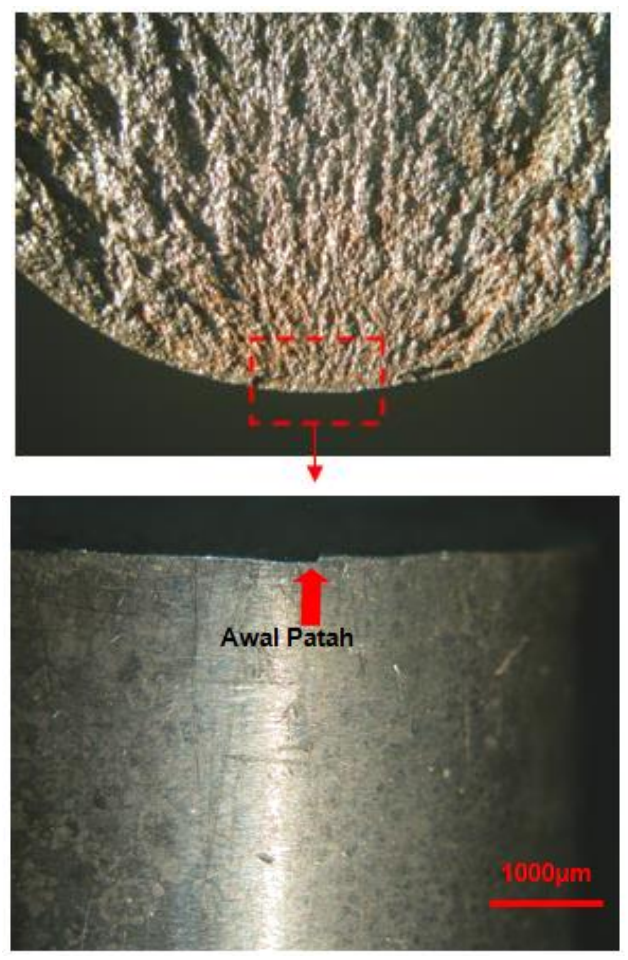

Gambar 8

Perbesaran Gambar 7 menunjukkan awal perpatahan pada Polished Rod

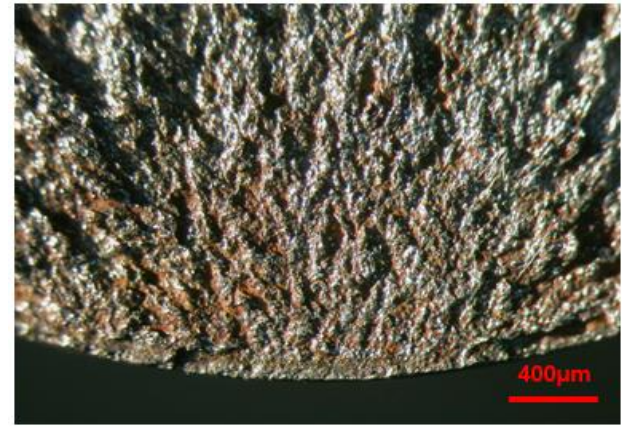

Gambar 9

Polished Rod mengalami patah getas dengan pola Radial Mark akibat Bending Load

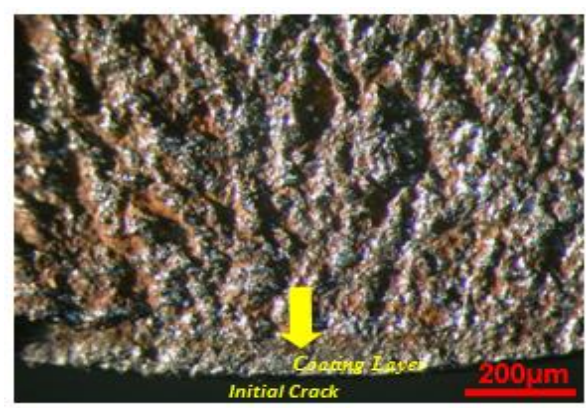

Gambar 10.

Daerah Coating Layer di daerah awal patahan masih terlihat jelas permukaan patahannya

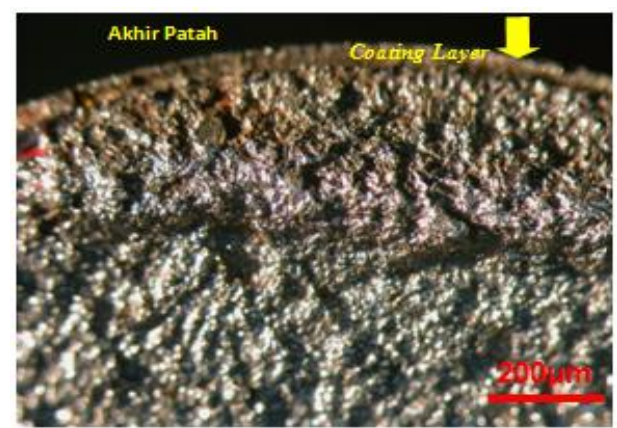

Gambar 11.

Daerah Coating Layer di daerah akhir patahan masih terlihat jelas permukaan patahannya

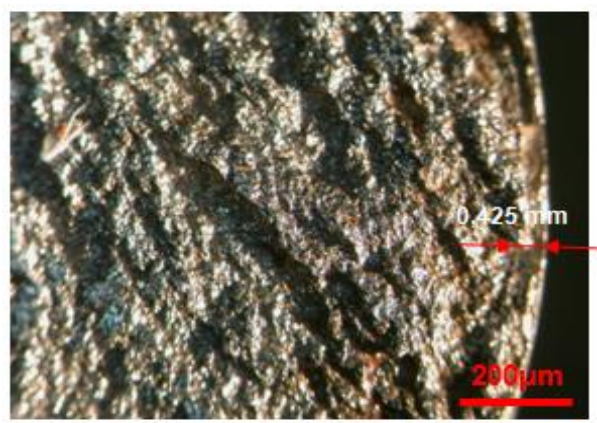

Gambar 12.

Ketebalan Coating Polished Rod sebesar $0,425 \mathrm{~mm}$ 


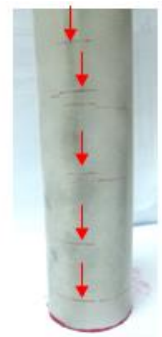

Gambar 13.

Hasil Uji Penetran pada permukaan luar Polished Rod kode putih menunjukkan adanya retak melintang dengan arah sumbu Rod (Panah) hanya pada satu sisi. Retak pada satu sisi menunjukkan bahwa Polished Rod mengalami beban Bending sebelum patah

\section{Hasil Pemeriksaan Metalografi}

Pemeriksaan metalografi yang dilakukan pada potongan memanjang polished rod (Gambar 14-16) menunjukkan adanya cacat porositas pada daerah coating layer (Gambar 17). Struktur mikro untuk daerah inti potongan memanjang polished rod kode putih berupa ferit (daerah terang)-perlit (daerah gelap), bainit, dan martensit (Gambar 18). Selain itu, pada daerah inti potongan memanjang juga terdapat cacat berupa inklusi (Gambar 18).

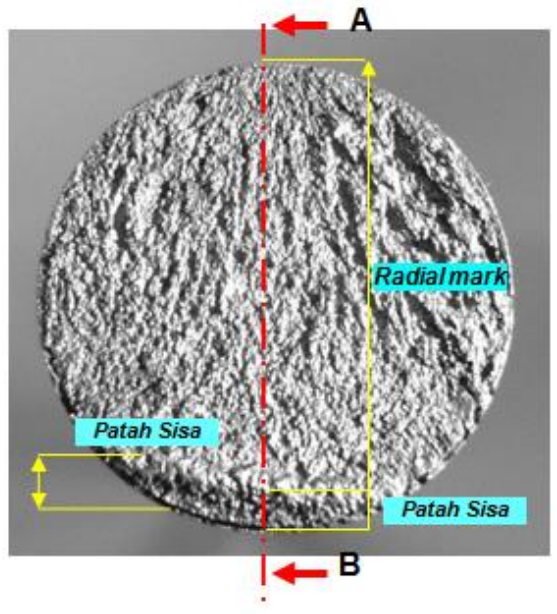

Gambar 14.

Potongan memanjang (A-B) menunjukkan adanya patah getas dengan pola

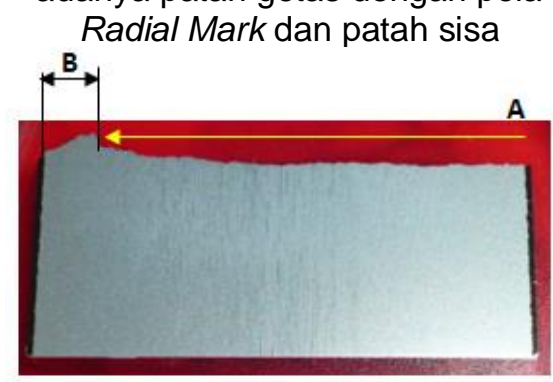

Gambar 15.

Sampel Metalografi potongan memanjang polished rod

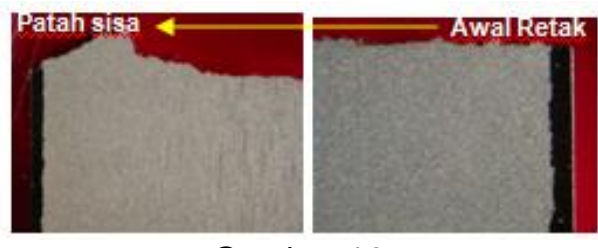

Gambar 16.

Foto Makro Etsa sampel metalografi potongan memanjang

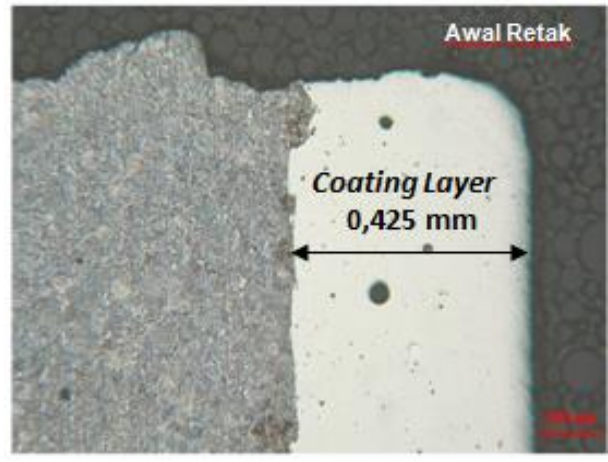

Gambar 17.

Hasil Metalografi pada daerah awal patah (a) Sampel Polished Rod menunjukkan adanya cacat porositas pada daerah Surface Treatment . Etsa : Kalling Reagent

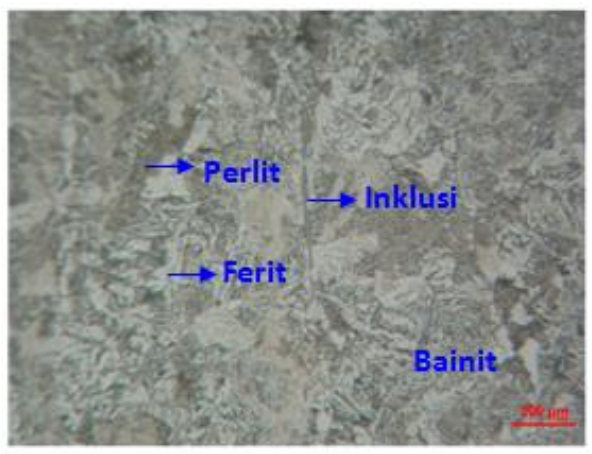

(a)

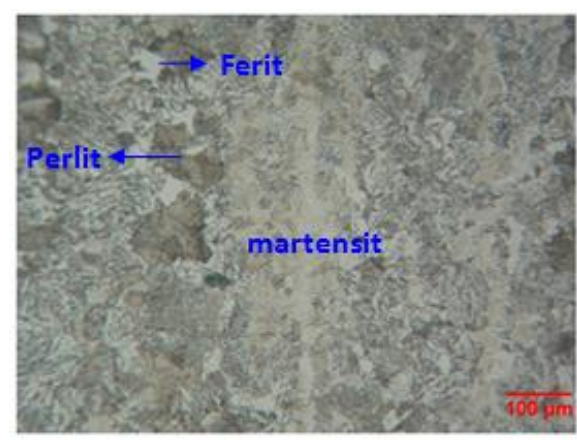

(b)

Gambar 18.

Hasil Metalografi sampel patahan Polished Rod Kode putih di daerah Inti berupa Ferit (Area Terang)-Perlit (Area Gelap), Bainit, dan Martensit dengan cacat Inklusi. Etsa : Nital $2 \%$ 
Sedangkan pada potongan melintang polished rod (Gambar 19) menunjukkan adanya cacat porositas dan retak pada daerah coating layer (Gambar 20). Retak yang muncul pada potongan melintang polished rod berada pada sisi dalam daerah coating layer. Struktur mikro untuk daerah inti potongan melintang polished rod kode putih berupa ferit (daerah terang)-perlit (daerah gelap), bainit, dan martensit (Gambar 21).

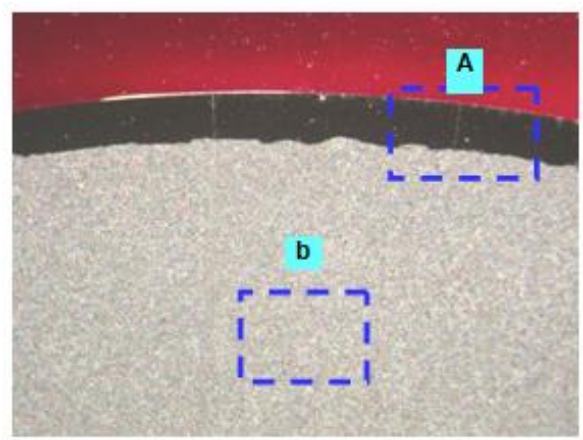

Gambar 19.

Sampel Metalografi potongan melintang Polished Rod

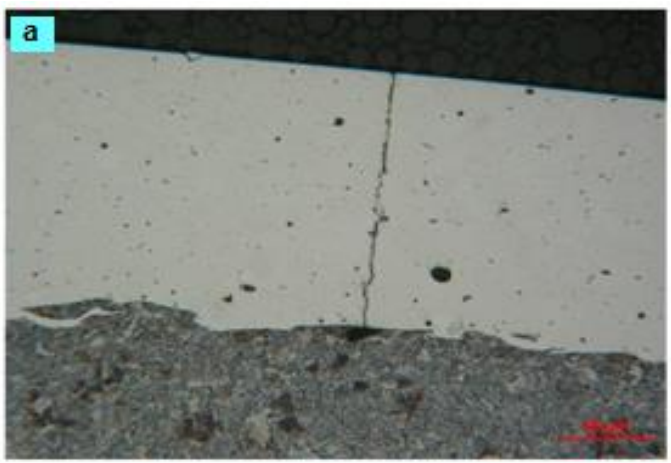

Gambar 20.

Hasil Metalografi sampel Polished Rod daerah a menunjukkan adanya retak dan cacat porositas pada daerah Surface

Treatment. Etsa : Kalling Reagent

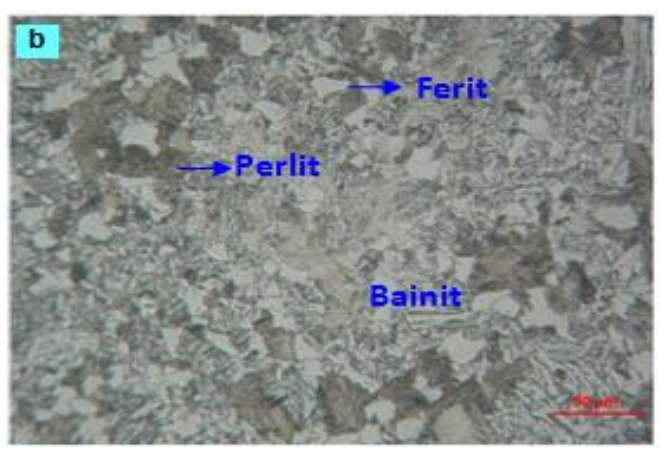

Gambar 21.

Hasil Metalografi Struktur Mikro pada Sampel Polished Rod Daerah c (Daerah Inti) berupa Ferit (Area Terang)-Perlit (Area Gelap) dan Bainit. Etsa : Nital 2\%

\section{Hasil Pengujian Kekerasan}

Pengujian kekerasan dari polished rod dilakukan untuk mengetahui perubahan sifat kekerasannya.

Hasil uji kekerasan polished rod dapat dilihat pada Tabel 2 serta lokasi pengambilan nilai kekerasan dapat dilihat Gambar 22.

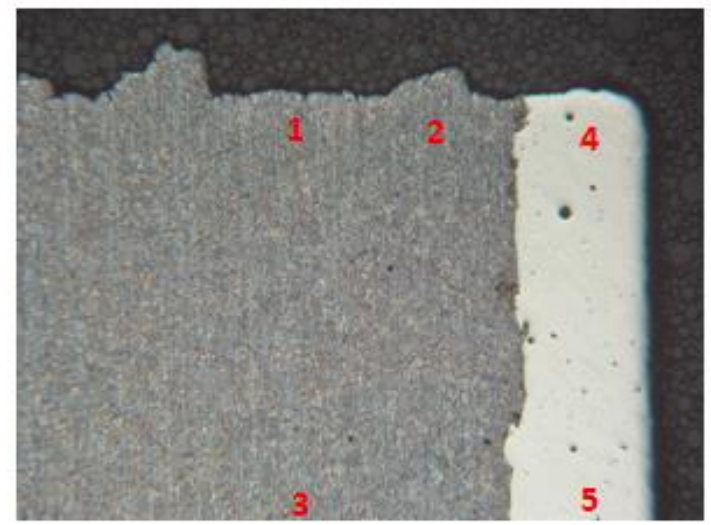

Gambar 22.

Sampel Uji Kekerasan Polished Rod

Tabel 2.

Hasil Pengujian Kekerasan Polished Rod

\begin{tabular}{ccc}
\hline No. & $\begin{array}{c}\text { Harga Kekerasan } \\
(\mathrm{HV})\end{array}$ & Keterangan \\
\hline 1 & 321 & Base Metal \\
& 306 & \\
2 & 313 & $\begin{array}{c}\text { Coating } \\
\text { Layer }\end{array}$ \\
\hline 4 & 687 & \\
5 & 685 & \\
\hline API 11B $^{9)}$ & Min. 480 & \\
\hline
\end{tabular}

Hasil uji kekerasan menunjukkan bahwa polished rod memiliki nilai kekerasan pada daerah inti (base metal) berada pada rentang nilai kekerasan 306 - 321 HV dan daerah surface treatment (coating layer) berada pada rentang nilai kekerasan $665-687 \mathrm{HV}$. Hasil uji kekerasan pada daerah surface treatment sesuai dengan standar API 11B tentang standar kekerasan spray metal coating (daerah surface treatment) yaitu minimal sebesar $480 \mathrm{HV}$.

\section{Hasil Analisa Komposisi Kimia}

Hasil analisa komposisi kimia polished rod dengan spesifikasi material standar dapat dilihat pada Tabel 3. Hasil analisa komposisi kimia menunjukkan bahwa material base metal polished rod tidak sesuai dengan production certificate 1045-2016-005 milik sebuah perusahaan, akan tetapi sesuai 
dengan komposisi material standar API 11 ${ }^{9)}$ dan AISI $4145^{10)}$ yang merupakan standar spesifikasi untuk polished rod.

Tabel 3.

Analisa Komposisi Kimia Material Polished Rod

\begin{tabular}{|c|c|c|c|}
\hline \multicolumn{4}{|c|}{ Polished rod } \\
\hline Unsur & $\%$ berat & $\begin{array}{c}\text { Prod } \\
\text { Cert. } \\
1045- \\
2016- \\
005\end{array}$ & $\begin{array}{c}\text { AISI } \\
4145^{1)}\end{array}$ \\
\hline $\mathrm{Fe}$ & 96,5 & Rem. & Rem. \\
\hline C & 0,441 & $\begin{array}{c}0,43- \\
0,50\end{array}$ & $\begin{array}{c}0,43- \\
0,48\end{array}$ \\
\hline $\mathrm{Si}$ & 0,232 & & $\begin{array}{c}0,15- \\
0,30\end{array}$ \\
\hline $\mathrm{Mn}$ & 0,881 & $\begin{array}{c}0,60- \\
0,90\end{array}$ & $\begin{array}{c}0,75- \\
1,00\end{array}$ \\
\hline $\mathrm{Cr}$ & 1,02 & $\begin{array}{c}0,10- \\
0,16\end{array}$ & $\begin{array}{c}0,80- \\
1,10\end{array}$ \\
\hline Mo & 0,232 & 0,02 & $\begin{array}{c}0,15- \\
0,25\end{array}$ \\
\hline$P$ & 0,0257 & $\begin{array}{c}\text { Maks. } \\
0,04\end{array}$ & $\begin{array}{c}\text { Maks. } \\
0,035\end{array}$ \\
\hline$S$ & 0,0307 & $\begin{array}{c}\text { Maks. } \\
0,05\end{array}$ & $\begin{array}{c}\text { Maks. } \\
0,04\end{array}$ \\
\hline
\end{tabular}

\section{Hasil Pengujian Tarik} Tabel 4.

Hasil uji tarik polished dapat dilihat pada Tabel 4

Hasil Pengujian Tarik Polished Rod

\begin{tabular}{cccc}
\hline No. & $\begin{array}{c}\text { UTS } \\
(\mathbf{M P a})\end{array}$ & $\begin{array}{c}\text { YS } \\
(\mathbf{M P a})\end{array}$ & $\begin{array}{c}\text { Elongasi } \\
(\%)\end{array}$ \\
\hline 1. & 1060 & 654,7 & 11,4 \\
2. & 1156,3 & 878,8 & 14,3 \\
3. & 1158,9 & 655,7 & 14,3 \\
API & $655-$ & N/A & N/A \\
$11 \mathrm{~B}^{[9]}$ & 1103 & & \\
\hline
\end{tabular}

Hasil uji tarik menunjukkan bahwa polished rod sesuai dengan spesifikasi untuk polished rod pada API 11B.

\section{Hasil Analisa SEM}

Hasil analisa dan pemeriksaan SEM (Scanning Electron Microscope) pada daerah patahan polished rod menunjukkan retak sekunder akibat beban bending (Gambar 23). Hasil analisa EDS (Energy Dispersive Spectroscopy) (Gambar 24) menunjukkan adanya analisa kualitatif unsur-unsur paduan polished rod seperti $\mathrm{Ni}, \mathrm{Fe}, \mathrm{C}, \mathrm{Al}, \mathrm{Si}$, dan $\mathrm{Cr}$ (Tabel 5).

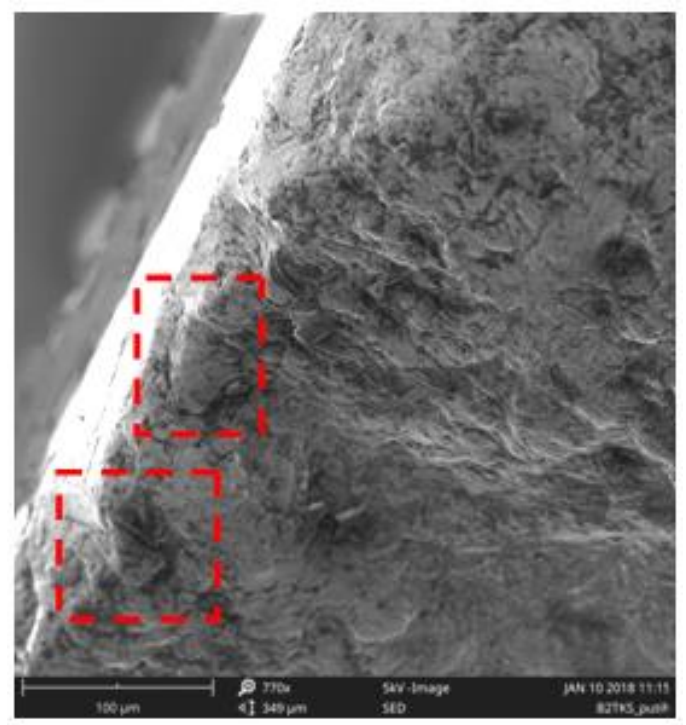

Gambar 23.

Analisa Mikro Fraktografi dengan SEM (Scanning Electron Microscope) pada Polished Rod menunjukkan adanya retak sekunder akibat beban Bending (kotak)

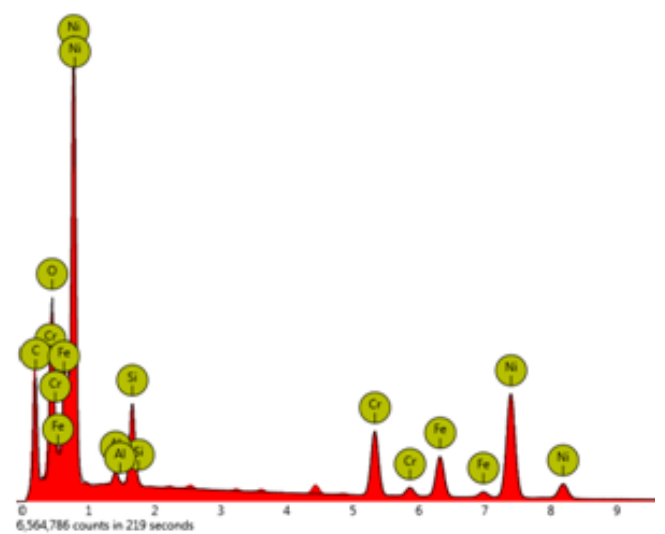

Gambar 24.

Hasil Spektrum EDS dari daerah patahan Polished Rod

Tabel 5.

Hasil Analisa Unsur pada daerah patahan Polished Rod

\begin{tabular}{cccc}
\hline \multicolumn{4}{c}{ Hasil analisa unsur pada daerah } \\
patahan polished rod \\
\hline Unsur & $\%$ berat & Unsur & $\%$ berat \\
$\mathrm{Ni}$ & 43,75 & $\mathrm{Fe}$ & 9,38 \\
$\mathrm{C}$ & 20,35 & $\mathrm{Si}$ & 3,55 \\
$\mathrm{O}$ & 12,79 & $\mathrm{Al}$ & 0,66 \\
$\mathrm{Cr}$ & 9,52 & & \\
\hline
\end{tabular}

\section{Pembahasan}

Hasil pemeriksaan nilai kekerasan (Tabel 2), kandungan komposisi kimia (Tabel 3), serta nilai kekuatan tarik (Tabel 4) menunjukkan bahwa base metal material polished rod tidak sesuai dengan production 
certificate 1045-2016-005, akan tetapi sesuai dengan komposisi material standar API 11B ${ }^{9)}$ dan AISI $4145^{10}$ yang merupakan standar spesifikasi untuk polished rod.

Dari hasil pemeriksaan fraktografi makro pada polished rod pada Gambar 7 dan Gambar 9 menunjukkan adanya permukaan patahan yang rata. Permukaan patahan yang rata merupakan ciri patah patah getas akibat pembebanan statik. Patah getas dengan pola radial mark memiliki alur patah berupa jejak radial memusat ke satu titik ${ }^{1-2,11-12)}$. Pola patah radial mark menunjukkan bahwa alur perambatan retak pada polished rod berlangsung dengan cepat ${ }^{1}$. Sedangkan beban bending ditandai dengan adanya retak melintang sekunder pada satu sisi ${ }^{1)}$ permukaan polished rod kode putih (Gambar 13). Retak melintang pada salah satu sisi menunjukkan bahwa salah satu sisi polished rod mengalami tegangan bending. Tegangan bending kemungkinan disebabkan karena terhalangnya sistem kerja polished rod yang disebabkan oleh masalah misalignment pada unit polished rod. Selain itu, dari hasil analisa SEM juga mengkonfirmasi adanya retak sekunder di permukaan patahan polished rod akibat pembebanan bending (Gambar 23).

Terdapat dua jenis retakan pada polished rod. Jenis retakan pertama merupakan retakan mikro dimana awal retak terjadi pada daerah coating layer bagian dalam ini disebabkan karena adanya cacat berupa porositas (Gambar 17 dan Gambar 20). Retak tersebut yang muncul dimulai dari batas antara material dasar dengan coating layer menuju keluar coating layer. Dengan keberadaan cacat bisa menjadi sumber awal retak jika ada tegangan bending yang berlebih. Jenis retakan yang kedua merupakan retak makro sehingga bisa dideteksi oleh uji penetrant. Retakan ini hampir merata pada satu sisi. Ini membuktikan adanya beban bending yang kemungkinan disebabkan karena masalah misalignment pada unit pompa angguk (sucker rod) $)^{1-2,13)}$.

Dari bukti-bukti yang ditemukan menunjukkan bahwa penyebab utama dari patahnya polished rod adalah adanya pembebanan bending yang mendadak ketika pompa angguk (sucker rod) beroperasi dan bergerak naik-turun. Beban bending tersebut bisa timbul kemungkinan akibat terhalangnya sistem kerja polished rod karena masalah misalignment maka polished rod tidak mampu menahan tegangan bending yang cukup besar melebihi kekuatan tariknya sehingga patah $^{1-2,12)}$.

\section{SIMPULAN}

Berdasarkan hasil pemeriksaan dan pengujian yang telah dilakukan pada polished rod dapat disimpulkan bahwa material polished rod bersifat getas dimana base metal material polished rod tidak sesuai dengan production certificate 1045-2016-005, akan tetapi sesuai dengan komposisi material standar AISI 4145 dan API 11B yang merupakan standar spesifikasi untuk polished rod

Hasil pemeriksaan metalografi menunjukkan bahwa mikrostruktur base metal material polished rod bersifat tidak homogen yang terdiri atas fasa ferit, perlit, martensit, dan bainit. Selain itu, pada struktur mikro polished rod ditemukan banyak cacat porositas pada daerah surface treatment (coating layer), namun cacat porositas bukan penyebab utama kegagalan polished rod.

Jadi, dapat disimpulkan bahwa penyebab kerusakan adalah ketidakhomogenan pada mikrostruktur dan sifat material yang bersifat getas yang berperan sebagai konsentrasi tegangan ditambah dengan tertahannya sistem kerja pompa angguk yang menyebabkan satu sisi polished rod mengalami pembebanan bending sampai material tidak mampu lagi menahan beban lalu patah.

\section{SARAN}

Agar dapat menghindari terjadinya perpatahan pada polished rod selanjutnya, maka perlu dilakukan tindakan pencegahan antara lain apabila ingin mendapatkan material yang sesuai beban desain maka perlu dilakukan pemeriksaan metalografi, uji kekerasan, dan uji tarik pada material polished rod yang umur pakai lebih dari 2 bulan sebagai pembanding.Selanjutnya perlu dilakukan identifikasi material secara acak pada material yang dibeli agar mendapatkan material yang dibutuhkan atau sesuai dengan beban desain. Selain itu, juga diperlukan pemeriksaan sistem kerja pompa angguk (sucker rod) apakah ada yang menggangu pergerakan polished rod sesuai SOP (Standard Operational Procedure) dan menghindari misalignment pada polished rod $^{14)}$.

\section{UCAPAN TERIMA KASIH}

Penulis mengucapkan terima kasih atas dukungan fasilitas laboratorium untuk penelitian analisa kerusakan ini yang disediakan oleh B2TKS terutama Laboratorium Analisa Kerusakan dan Umur Sisa. 


\section{DAFTAR PUSTAKA}

1. Green, Justin \& Harbishon Fischer, "Polished Rod Failure Preventation", 3rd edition, Oklahoma City, 2013

2. Dover, Norris, "A Special Report from Norris : Sucker Rod Failure Analysis", Dover Artivicial Lift, 2013

3. ASTM E3-01, "Standard Guide for Preparation for Metallographic Specimens", ASTM, 2003

4. ASTM E407-07, "Standard Practice for Microetching Metals and Alloy", ASTM, 2007

5. SNI 19-0409-1989, “Uji Kekerasan Vickers", SNI, 1989

6. William D.Callister Jr., "An Introduction : Material Science and Engineering," John Wiley \& Son, Inc., hal. 373, 2007

7. ASTM E415-17, "Standard Test Method for Analysis of Carbon and Low-Alloy Steel by Spark Emission Spectroscopy, ASTM, 2017

8. ASTM E8, "Standard Test Methods for Tension Testing of Metallic Materials", ASTM, 2003
9. API Specification11B, "Standard Specification for Sucker Rod, Polished rods and Liners, Couplings, Sinker Bars, Polished rod Clamps, Stuffing Boxes, dan Pumping Tees", 2nd edition, American Petroleum Institute (API), 2010

10. ASM Metal Reference Book 3rd Edition, 2003

11. Jamoko, Bayu, Triyono, Eko Prasetya Budiana, "Analisa Kegagalan Pegas Ulir pada Bogie Type NT 11 untuk Gerbong Kereta Ekonomi”, Mekanika, Vol. 12, No.2, Maret 2014

12. Dieter, George E, Mechanical Metallurgy 3rd edition, McGraw-Hill, 2010

13. Moises, G.V.L., dkk, "Sucker-Rod Pumping Failure Diagnostic System", SPE Annual Technical Conference \& Exhibition International, SPE SPE134975-PP, 2013

14. Poythress, Mike, "Depending on Something Other Than to Reduce Your Rod Pumping Failure Rate", John Crane Production Solutions Inc., 2012. 
(halaman ini sengaja dikosongkan) 